\title{
DESAFIOS E OPORTUNIDADES DO BUDISMO NO BRASIL: RELATO DE UM SIMPÓSIO COM TRADUTORES/ACADÊMICOS BUDISTAS ${ }^{1}$
}

\author{
Luciana Fernandes Marques \\ Denise Mara Robson \\ Giuseppe Ferraro \\ Joaquim Antônio Monteiro \\ Maria Beatriz Bispo Florencio \\ Marlos Tadeu Bezerra de Mello \\ Ricardo Sasaki
}

1 Como citar: MARQUES, Luciana Fernandes; ROBSON, Denise Mara; FERRARO. Giuseppe; MONTEIRO, Joaquim Antônio; FLORENCIO, Maria Beatriz Bispo; MELLO, Marlos Tadeu Bezerra de; SASAKI, Ricardo. Desafios e oportunidades do budismo no Brasil: relato de um simpósio com tradutores/acadêmicos budistas. Debates do NER, ano 21, n. 40, p. 367-390, 2021.

2 Luciana F. Marques é doutora em Psicologia e professora da Faculdade de Educação da Universidade Federal do Rio Grande do Sul, Brasil. E-mail: luciana.marques@ufrgs.br. Denise M. Robson é mestre em Core Process Psychotherapy (Psicoterapia baseada na Psicologia Budhista e Mindfulness), pela Karuna Institute \& University of Essex, Inglaterra, e presidente do Centro de Dharma Buda da Compaixão, Brasil. E-mail: denise.robson@ gmail.com. Giuseppe Ferraro é doutor em Filosofia e professor visitante da Universidade Federal de Minas Gerais, Brasil. E-mail: giuseppeferraro2003@yahoo.com.br. Joaquim A. Monteiro é doutor em Filosofia Budista pela Universidade de Komazawa, Tóquio, Japão e participa do Instituto Zen Maitreya. E-mail: yasudarijin55@gmail.com. Maria B. B. Florencio é Tradutora/Intérprete para o Português de S.S. Dalai Lama, Índia. E-mail: biabispo@gmail.com. Marlos T. B. de Mello é doutorando em Educação pela Universidade do Vale do Rio dos Sinos e professor licenciado de Filosofia e Ensino Religioso da Escola Estadual Bento Gonçalves, Porto Alegre, Brasil. E-mail: marlos-mello@educar.rs.gov.br. Ricardo Sasaki é Psicólogo pela Universidade de São Paulo e Diretor Presidente do Centro de Estudos Buddhistas Nalanda, Brasil. E-mail: ricardo@nalanda.org.br. 
Resumo: A partir de um Simpósio Virtual ocorrido em agosto de 2020 com praticantes e estudiosos do budismo, alguns deles tradutores budistas de diversas línguas (chinês, japonês, tibetano e sânscrito) para o português, emergem várias questôes. A motivação deste encontro foi a de dialogar sobre importantes questóes sobre o budismo no presente momento que vivemos, suas oportunidades e desafios. Ao longo do debate fica evidente o grande hiato cultural entre o Brasil e os países asiáticos. Igualmente se revela a sofisticação e rigor necessários às traduçóes bem como a necessidade e a dificuldade de estabelecer esse debate na academia. Este artigo apresenta os pontos mais importantes de cada exposição, os coloca em perspectiva e encaminha consideraçóes finais sobre os desafios e oportunidades presentes no amplo tema das traduçóes e do diálogo acadêmico com o budismo.

Palavras-chaves: ciência e religiāo; budismo; filosofia oriental

CHALLENGES AND OPPORTUNITIES OF BUDDHISM IN BRAZIL: REPORT OF A SYMPOSIUM WITH BUDDHIST TRANSLATORS/ACADEMICS

\begin{abstract}
Several questions emerged from a Virtual Symposium that took place in August 2020 with practitioners and scholars of Buddhism, some of them Buddhist translators from different languages (Chinese, Japanese, Tibetan and Sanskrit) into Portuguese. The motivation of this meeting was to discuss important questions about Buddhism in our day and age, its opportunities and challenges. Throughout the debate it became evident that there is a great cultural gap between Brazil and Asian countries. It also reveals the sophistication and rigor required for translations, as well as the need and difficulty of establishing this debate in academia. This article presents the most important points of each speech, puts them in perspective and makes final considerations about the challenges and opportunities present in the broad topic of translations and academic dialogue with Buddhism.
\end{abstract}

Keywords: science and religion; buddhism; eastern philosophy.

A partir de um Simpósio Virtual ocorrido em agosto de 2020 com praticantes e estudiosos do budismo, alguns deles tradutores budistas de diversas línguas (chinês, japonês, tibetano e sânscrito) para o português, emergiram várias questóes. A motivação deste encontro foi a de dialogar sobre importantes questóes sobre o budismo, no Brasil, no presente momento 
que vivemos, suas possibilidades e desafios. Neste contexto, um assunto que surgiu como fundamental foi a já conhecida (Meneses, 2017; Beluzzi, 2015) dificuldade de tradução para língua portuguesa de textos budistas. Ao longo do debate ficou evidente no grupo o grande hiato cultural entre o Brasil e os países asiáticos, sendo estes a origem dessas tradiçóes. Igualmente se revela ao leitor menos versado no tema a sofisticação e rigor necessários às traduçôes bem como a necessidade e a dificuldade de estabelecer esse debate na academia. E, ainda, a falta de diálogo, troca ou mesmo conhecimento do potencial humano e expertise já existentes no país para tradução desses textos. Em função da relevância de tal discussão na academia, este artigo visa apresentar e comentar o conteúdo surgido nesse evento.

Uma questáo apresentada, que foi uma das motivadoras para esse encontro, foi a constatação da falta de conhecimento e participação do público que estuda o budismo fora da academia sobre os eventos organizados pelas universidades. Ou seja, a falta de diálogo, de intercâmbio e de troca de experiências acaba formando um muro entre esses dois contextos de produção de conhecimento: a academia e as comunidades (tradiçóes).

No evento nacional da Associação Nacional de Pós Graduação em Filosofia em outubro de 2018, na Universidade Federal do Espírito Santo (UFES), assim como em outros eventos de Ciências das Religióes e Estudos da Religião, alguns desses tradutores/acadêmicos e estudiosos não ligados à academia estiveram presentes. Esses raros eventos e situaçóes congregam parte do público que circula entre a academia e as tradiçóes budistas, em que, provavelmente, são considerados muito acadêmicos para ficarem apenas na tradição de origem e muito religiosos para ficarem apenas na academia - são chamamos para fins deste escrito de tradutores praticantes/acadêmicos. Todos eles são praticantes budistas em alguma medida (são ou foram monges e/ou professores de budismo e seguidores dos ensinamentos do Buda) e a maioria deles teve alguma passagem por universidades. Mais adiante aqui, pela descrição das trajetórias e de suas falas ficará mais evidente essa nomenclatura e seus vieses. Muito do que aqui discutiremos, como as principais preocupaçóes deles, se refere a esses e outros pontos cegos que não têm encontrado muitos fóruns coletivos e universitários de expressão. 
A organizadora do Simpósio, Denise Robson, promoveu o encontro imbuída por essas questóes, que visivelmente se apresentam para os tradutores/praticantes/acadêmicos, apesar de ela própria ter como experiência a tradução restrita aos textos litúrgicos e ensinamentos orais de seu principal professor de budismo durante suas visitas ao Brasil. Ainda que haja o antagonismo presente de modo implícito no binômio religiáo-ciência, e que o grupo reunido náo traduza textos de uma mesma língua para o português, também se acrescenta o fato de os indivíduos serem provenientes de diferentes escolas budistas: Budismo Theravada, Zen, Yogachara e Vajrayana. Um consenso geral no grupo parece ser o de que o budismo se encontra em uma fase de expansão e florescimento no assim chamado Ocidente (países não asiáticos) e há uma preocupação sobre como se dará essa continuidade, especificamente no Brasil, tendo em vista as variadas segmentaçóes, ramificaçôes e uma ausência de diálogo em suas diversas expressóes.

Tendo esses questionamentos em vista e o brevíssimo cenário aqui apresentado, o objetivo deste artigo é apresentar as principais preocupaçóes de cinco principais expoentes do Simpósio, considerados aqui como praticantes/ tradutores/acadêmicos. Considera-se que suas falas são emblemáticas por ilustrarem os bastidores da vinda do budismo para o Brasil, a sua relaçáo com a universidade e quais os desafios de traduzi-lo para nossa língua, sociedade e cultura. O escrito bruto deste artigo foi trabalhado tecnicamente e é oriundo da transcrição da fala de cinco "tradutores praticantes/acadêmicos" que é apresentada, tensionada e discutida. As discussóes e comentários aqui presentes foram escritas e revisadas por todos os autores. Dessa forma, considera-se fruto da concordância da maior parte do grupo.

\section{Abertura do Simpósio de tradutores por Denise Robson}

Denise é Assistente Social, Psicanalista, Mestre em Psicoterapia baseada em Mindfulness pela UKCP, Inglaterra, e praticante budista há 20 anos.

$\mathrm{Na}$ abertura do Simpósio, Denise enfatiza o quanto o budismo não é homogêneo, mas sim rico, diverso, contraditório e paradoxal - ideia confirmada 
pelo estudo de Barrozo (2016). De nenhuma forma isso sugere falta de consistência, mas, ao que tudo indica, diferentes faces que ele foi adotando em diferentes culturas e épocas sem que o seu sentido original fosse deturpado. Nessa variedade, observa-se o seu desenvolvimento no âmbito de grupos de estudo e prática, no contexto supostamente mais religioso daqueles que estudam e praticam o budismo como caminho para a transformação pessoal, cujo objetivo é a iluminação. Como também, pelo budismo no âmbito acadêmico, especialmente fora do Brasil, na área de Estudos Budistas e Budologia. Ainda que na academia brasileira os trabalhos sejam esparsos e pulverizados em diferentes linhas de pesquisa, sua presença é inegável. Trabalhos como a tese de doutorado de Giuseppe Ferraro, que ganhou o prêmio de melhor Tese na ANPOF em 2014 é o reconhecimento de que as pesquisas com enfoque no budismo desenvolvidas no Brasil têm peso e valor significativo no âmbito da academia, bem como uma qualidade inegável.

A história do budismo é toda entremeada com universidades, sendo a primeira e a mais conhecida a Universidade Nalanda do Século II ao XII, da Índia, em que grandes eruditos e filósofos eram, também, monges e renomados praticantes de alta realizaçáo espiritual. $\mathrm{O}$ ambiente rigoroso de estudo e prática fazia desse centro de saber um guardião natural do significado profundo do ensinamento original do Buda. Mas diferente daquela época, hoje parece haver por parte da academia certa desconfiança em estudar religiōes (e entre elas o budismo), em especial, fora da área das Ciências das Religióes. Talvez um dos motivos dessa desconfiança seja o que aponta Carlucci (2015), o fato de muitos acadêmicos ocidentais que pesquisam e traduzem textos budistas são abertamente praticantes do budismo e discípulos de professores budistas tecendo uma rede complexa de significados pouco pesquisada.

Da parte dos budistas igualmente há desconfiança de que a academia possa deturpá-lo numa excessiva racionalidade, justamente o que a Universidade Nalanda buscava desconstruir através da Filosofia do Caminho do Meio e de um pensamento altamente analítico. Incluía em seu escopo a verdade absoluta, a vacuidade, temas como renascimento e etc. que podem 
parecer demasiado esotéricos ao academicismo vigente. De Nalanda para cá, as universidades se tornaram centros de racionalidade e intelectualidade que em nada remetem ao estilo de Nalanda que era um espaço de silêncio, contemplação, transformação da mente aliada à análise, dialética, debate e escrutínio das afirmações e suas consequências (Bronkhorst, 2007).

Esse, entretanto, não é um motivo para que o diálogo entre o budismo e a ciência não viceje. Ao contrário, a academia tem muito a enriquecer com a provocação do budismo de escrutinar as origens dos conceitos e das formulaçôes, bem como a fazê-lo com base numa motivação benéfica a si, ao mundo, aos seres e ao planeta. Conforme foi discutido no encontro, o budismo tem muito a se beneficiar ao ter nas universidades aliadas e guardiãs de rigorosos estudos padronização da linguagem e documentaçóes históricas, que de outra forma se perderiam em organizaçóes disseminadas pelo país afora sem o compromisso integrado de deixar um legado às futuras geraçóes. Por outro lado, algumas práticas acadêmicas podem levar ao cientificismo ao não reconhecer o conhecimento desenvolvido sobre outras bases, como é o caso da Filosofia e das tradiçôes. No caso do budismo, muito do conhecimento gerado não se deu apenas dentro das instituiçóes religiosas, filosóficas ou acadêmicas, mas sim na individualidade de praticantes reclusos que desenvolviam alto grau de entendimento e realização através da prática direta e em isolamento. Parece ser um desafio reconhecer a importância da academia para o desenvolvimento dos estudos budistas, já que o budismo como campo de conhecimento sobreviveu sem as universidades ocidentais por mais de vinte séculos.

\section{Professor Joaquim Monteiro}

O professor Joaquim Monteiro (Reverendo Shaku Shoshin) viveu 18 anos no Japão. É formado em Psicologia, tem Mestrado e Doutorado em Estudos Budistas pela Universidade de Komazawa, Japão. É tradutor de textos budistas do Japonês e do Chinês para o Português. Autor de publicaçóes no Brasil e exterior (apenas para citar algumas, ver Monteiro, 2019, 2016, 2015). 
O prof. Joaquim inicia a sua fala apontando um primeiro ponto de partida para a discussão sobre o diálogo entre a universidade e o budismo, ou como ele diz: a existência de duas perspectivas diferentes do budismo no Brasil, a perspectiva dita confessional e a perspectiva acadêmica. Ele conta que o evento da ANPOF de 2018, mencionado por Denise, não teria sido o primeiro a ter praticantes budistas vinculados a grupos confessionais manifestando-se como tal num evento acadêmico. Ele relata que anos antes houve um Simpósio de Filosofia Oriental na USP em que uma praticante criticou o fato de budistas estarem levando o budismo para a academia num comportamento similar ao de uma heresia ou profanação. Esse relato ilustra a desconfiança de alguns budistas em dialogar com a academia. Nesse evento de 2018 não houve manifestaçóes do tipo e, ao contrário, segundo o seu relato, a interlocuçáo foi frutífera e motivou a integraçáo desse grupo que veio encontrar-se outra vez por ocasiáo do Simpósio Virtual aqui apresentado.

Prof. Joaquim relembra outros fatos para ilustrar a questão do diálogo do budismo com a universidade. Em torno de 2010, o convidaram para participar de um encontro na Universidade Federal Fluminense no Rio de Janeiro para um estudo sobre a obra de Nagarjuna. Ele disse ter se sentido tremendamente impactado pelo alto nível de estudo vinculado. Explica que, quando iniciou seus estudos do budismo na academia em 1985, essa era uma época em que o único lugar onde se podia estudar alguma coisa sobre o budismo na academia brasileira era no Departamento de História da USP, em função da presença do professor Ricardo Mário Gonçalves (algumas de suas publicaçóes: Gonçalves, 2005, 1988, 1972). Mas ele foi percebendo que com o passar do tempo duas grandes mudanças ocorreram no budismo brasileiro: a primeira, a nível acadêmico, foi o fato de existirem grupos de pesquisa organizados com alguns especialistas que dominam o sânscrito, o tibetano, o chinês, as línguas ditas clássicas; o fato de já existir uma interlocução e uma produção séria, incluindo traduções diretas dos originais revelava um avanço irrecusável de notável importância. De outro lado, no nível confessional, a totalidade dos grupos budistas que existiam no Brasil em 1985 não davam nem a décima parte de apenas um 
dos grupos budistas que existem hoje entre dezenas. Ou seja, conforme o prof. Joaquim, o budismo hoje em dia continua sendo uma prática espiritual minoritária, uma corrente de espiritualidade minoritária no Brasil se comparada com as outras religióes, mas quando comparado consigo mesmo, cresceu prodigiosamente e se passou a reconhecer a presença de uma Sangha brasileira (grupo de praticantes). Essa percepção pode ser confirmada pelo estudo de Usarski e Shoji (2017).

A história do prof. Joaquim é singular ao mostrar questóes fundamentais que não apenas se referem à sua história em particular mas ilustram de um modo mais amplo os embates enfrentados no diálogo entre budismo e academia. Ele conta que nos anos em que estudou no Japão, iniciou numa perspectiva confessional mas sentiu uma série de problemas e contradições que o levaram a se voltar para o campo acadêmico. Entre os anos de 1985 e 1988, enquanto ainda estava envolvido com a perspectiva confessional budista na Verdadeira Escola da Terra Pura, Jodo Shinshu, foi que percebeu alguns desses problemas. Em 1988, a convite do Professor Obata Bunsho, passou a integrar a equipe de pesquisa do Centro de Estudos de Cultura Budista da Universidade. Nessa época iniciou-se uma transição dos seus estudos confessionais para os estudos acadêmicos. Ele estudava a Filosofia do Kyogyoshinshô e diversas correntes da doutrina tradicional dentro do Jodo Shinshu quando começou a sentir muitas limitaçôes, talvez em função de já estar se aclimatando com o ambiente acadêmico. Uma dessas limitaçôes se refere à metodologia dos estudos budistas na vertente confessional da Escola da Terra Pura em que ele percebia uma certa tendência em se "absolutizar” o patriarca fundador, sendo essa uma figura considerada intocável. Naturalmente certos dogmas ou crenças próprias dessa tradição acabariam por ser revelados ao se adotar uma postura mais científica de investigação.

Ele dá exemplos indicando que ler e estudar os textos de maneira confessional pode fazer vista grossa às mudanças e contradições dos ensinamentos de ditos mestres. Esses elementos levaram a uma guinada no seu percurso e a momentos de ruptura com o que fizera até então. Nessa transição, nos anos de 1989, 1990 e 1991, passou a ter contato com a Universidade de 
Komazawa, em Tóquio, considerada a principal universidade do Soto-shu, Escola Japonesa de Zen Budismo. Foi um tempo em que sua perspectiva sofreu transformaçôes até a entrada no Mestrado no Departamento de Estudos Budistas de Komazawa em 1995 quando passou a adotar uma metodologia completamente diferente da anterior num trabalho estritamente acadêmico de estudos budistas. Mas, como ele dirá adiante, não se tratava de mudar de um cenário confessional com problemas para adotar uma perspectiva acadêmica sem problemas.

Dentro dos chamados estudos budistas modernos - que, segundo ele, é uma modalidade de estudos que não inicia na Ásia e nem no Japão mas no ocidente a partir do século XVIII - há uma valorização dos estudos "objetivos", que trabalham a partir de perspectivas históricas e filológicas, em que se aprende a fazer o mapeamento histórico filológico dos textos. $\mathrm{O}$ prof. Joaquim, após ter ilustrado a limitação de incrementar um pensamento mais acadêmico num contexto confessional, agora conta as limitaçóes de ser um praticante budista trabalhando na academia. Comenta que, para aqueles que pretendem se tornar acadêmicos budistas, ocupar um cargo na Universidade e ganhar a vida com isso, os chamados estudos mais objetivos, não é uma das piores opçôes. Nessa situação pode-se adotar uma perspectiva acadêmica e manter a perspectiva do budismo enquanto um valor essencial para a sua vida. Muitos dos que buscam o budismo, o fazem no intuito de elucidar a existência, de trazer alguma mudança essencial para a vida. Mas, ao trabalhar com o budismo na academia, esse aspecto passa a ser questionado em prol de uma suposta objetividade. $\mathrm{Na}$ medida em que a metodologia objetiva-positivista pretende cultivar a objetividade e uma séria pretensão de neutralidade, ela pode entrar em contradição com as questôes propriamente budistas da vida pessoal.

Isso tudo ficou mais claro quando o prof. Joaquim foi para Komazawa, um ambiente privilegiado aos estudos, e acompanhou professores do Budismo Crítico como Noriaki Hakamaia e Okabe Kazuo. Eles tinham uma forte formação em termos da história da filologia e dessa metodologia, com uma perspectiva extremamente filosófica de abordagem do budismo, não filosófica 
no sentido de interpretar o budismo a partir da filosofia ocidental, mas de elucidar qual é o ponto de vista filosófico do próprio budismo. Em sua tese de doutorado (Monteiro, 2021) elucidou essas duas metodologias e propôs uma terceira, a qual chamou de Budologia Crítica, que pressupóe a existência de todos esses avanços nos estudos históricos filológicos do budismo, mas parte do ponto de vista filosófico que é frequentemente encontrado no contraste ou até mesmo no confronto com a filosofia ocidental.

Dessa época em diante os desafios que o prof. Joaquim relata encontrar se localizam na função de tradutor no Brasil em relação à compreensão profunda necessária para traduzir certos termos e, ao que parece, não há consenso acerca disso.

\section{Professor Ricardo Sasaki}

O prof. Ricardo Sasaki é Diretor-Presidente do Centro de Estudos Buddhistas Nalanda, com um trabalho de três décadas de escrita e tradução, além de psicólogo clínico formado pela USP. É ministro de Dharma e professor autorizado na tradiçấo buddhista. Ele publicou vários trabalhos nacionais e internacionais (para citar apenas dois: Sasaki, 2017 e 1995). Entre suas atividades atuais está a tradução de uma grande coletânea de textos canônicos e extra canônicos das três maiores tradiçōes - Theravāda, Mahāyāna e Vajrayāna - em associação com uma universidade tailandesa.

Ele começa sua fala voltando-se para as questôes técnicas e desafiadoras da tradução em si. Esclarece que a tradução não se restringe a apenas traduzir uma língua para outra, mas sim focar em como transpor o significado de um contexto para outro. No caso do budismo, que é basicamente asiático, oriental, regional e oriundo de vários lugares da Ásia, ao chegar no Brasil será traduzido como um todo e não apenas as suas palavras; ou, como diria Bezerra (2012), há uma interpretação criadora. Nesse sentido, considera que a tradução de um texto religioso contém duas áreas principais e, por vezes, opostas. Uma delas julga a palavra como sagrada. Isso é comum na tradição hindu que tem especial relevância para os budistas. Igualmente, 
é observada no Islã, já que o Corão é considerado a palavra de Deus e, enquanto palavra de Deus, não pode ser traduzida. Isso significa que se você quiser ser muçulmano você deve aprender o árabe para ler na língua original, pois toda a tradução, nesse caso, é, e sempre foi, muito mal vista. Continua dizendo que, em certo sentido, o hebraico também tem aspectos filosóficos que estão muito conectados com as palavras usadas. Toda a tradição cabalística do Zohar, que analisa as palavras e os significados numéricos, carrega essa ideia da língua Sagrada. Na tradução hindu, o sânscrito também tem, frequentemente, essa conotação, o que é visto, por exemplo, na ênfase em pronunciar um mantra de forma correta.

Para o budismo, a realidade como um todo, incluindo a linguagem, é vista como um fenômeno. Pode-se ter palavras diferentes apontando para uma mesma experiência, para uma mesma realidade. Em termos do ensinamento mais antigo do Buda, há essa noção de palavra enquanto convenção. O que é uma coisa que se contrapóe muito fortemente à noção da palavra enquanto verdade, enquanto expressão da verdade. Essa visão budista de palavra como convenção incentiva a tradução, ao contrário do outro modo em que somente através da língua original pode-se ter um contato direto e verdadeiro com o conteúdo. $\mathrm{O}$ prof. Ricardo acredita no incentivo à traduçáo pela ideia da palavra como convençáo, e isso pode ser visto naquelas palavras do Buda que estão no cânone, onde ele fomenta a tradução do Dharma para línguas locais, o que é um grande encorajamento para os tradutores e que desencorajamento aos professores das línguas originais.

Um outro problema a que ele se refere é: se há o incentivo de que a tradução ocorra, então como ela deve ser feita? E disso surge outra questão, uma dualidade: ela deve ser feita por meio de uma exatidão, um literalismo da tradução, da letra ou a ênfase deve ser colocada no sentido? Há prós e contras em ambos os extremos. Inicialmente pode-se pensar que o sentido é mais importante do que a perfeita adequação de uma língua para outra. Mas ele alerta que há o risco de essa ênfase prejudicar a tradução, visto que o componente subjetivo do tradutor participa em maior medida. $\mathrm{O}$ tradutor traz as suas tendências, os seus condicionamentos, as suas preferências, os seus

Debates do NER, Porto Alegre, ANo 2I, N. 40, P. 367-390, Ago./DeZ. 202 I 
preconceitos. Sendo um termo budista, o objetivo não apenas é uma tradução técnica perfeita, mas, também, expressar em outra língua o ensinamento do Buda, o que ele realmente quis dizer. Para isso seria necessário que o tradutor tivesse passado por algumas experiências para que ele próprio pudesse expressar os significados com propriedade. Porque essa tradução vem também da experiência dele, de sua compreensão do sentido, e não simplesmente da tradução literal. A partir dessas reflexôes, o prof. Ricardo indaga: qual é o limite da interpretaçáo do tradutor para conferir sentido ao texto original? Como se resolve esse componente da subjetividade na academia?

Botelho (2006) faz uma síntese interessante desse ponto mostrando a subjetividade e as preferências dos tradutores:

É comum um tradutor ou intérprete, mais apegado a prioridade do tema, criticar outros tradutores, mais inclinados à prioridade da língua e da gramática, por encobrirem ou deformarem o significado de certas passagens, bem como, deturparem o significado de termos técnicos, em virtude do excessivo zelo pela gramática. Já um tradutor mais apegado à gramática não se cansa de apontar as violências, os atropelos e os pisoteios na gramática sânscrita, cometidos por outros tradutores, mais deslumbrados pelo tema, no afä de chegarem ao significado e à interpretaçấo pretendidos (Botelho, 2006, p. 73).

Em boa parte das traduções o que se observa é uma possível intromissão, que pode ser excessiva ou esclarecedora, da pessoa do tradutor, do seu componente subjetivo. Por outro lado, quando a questáo é a de traduzir seguindo a exatidão da letra, então a pergunta se torna: "será que as palavras têm de fato um significado preciso?". Todos os tradutores sabem que nấo, que as palavras não têm. $O$ prof. Ricardo esclarece que no dicionário certas palavras podem ter dez significados, mesmo em sânscrito ou chinês podem ter vários significados. Então, qual seria a escolha do tradutor? Geralmente, depende do contexto também, mas ainda assim há uma escolha a ser feita. Como o tradutor escolhe as suas palavras? Outras vezes, mesmo que exista um significado, as palavras não correspondem completamente. Quem traduz línguas orientais sabe que elas têm algo além. Você tem aquela palavra mas mesmo que você a traduza 
parece que algo está faltando e é aí que entram as notas de rodapé. Geralmente as notas de rodapé explicam o que é, mas também o que pode significar o termo, nessa dimensão e em outras. Dessa forma, explicaçôes são adicionadas visando dar transparência ao sentido, à experiência, ao condicionamento do tradutor, que é figura central na interpretação das palavras. É ele quem está apresentando esse conteúdo em outra língua.

\section{Professor Giuseppe Ferraro}

Giuseppe Ferraro é Professor de Filosofia e autor da tradução comentada dos Versos Fundamentais do Caminho Meio (Mūlamadhyamakakārikā). É tradutor do Sânscrito para o português. Pós-doutor e estudioso do pensamento de Nāgārjuna (algumas de suas publicações, Ferraro, 2016, 2012 e 2011).

O prof. Giuseppe nasceu na Itália e iniciou sua fala no Simpósio contando como era forte a tradição de estudos indológicos na Universidade La Sapienza de Roma. Nessa mesma universidade ele cursou filosofia e foi onde começou a estudar sânscrito e filosofia da Índia com professores contemporâneos renomados. Fez mestrado e a seguir iniciou um doutorado que não concluiu, na Universidade de Pune na Índia. Anos depois retornou ao doutorado no Brasil, na UFMG, sob a orientação de Leonardo Vieira, focando no pensamento Madhyamaka e na história da filosofia budista indiana. É do prof. Giuseppe a primeira tradução do sânscrito para o português dos "Versos fundamentais do Caminho do Meio" (Mūlamadhyamakakārikā) de Nāgārjuna (e do livro "Dissolução das controvérsias" Vigrahavyāvartanī, no prelo).

Giuseppe inicia sua fala aprofundando a questão da presença do componente subjetivo do tradutor durante o processo de tradução. Ele afirma que essa presença é inegável e, de certa forma, inevitável. Cita Heidegger ao sentenciar que a abordagem que alguém faz de algo é sempre hermenêutica, ou seja, filtrada pelas características da formação individual, experiências e idiossincrasias. Segundo ele, esse componente reduz a capacidade do tradutor de ex-egese, isto é, a capacidade de extrair o significado autêntico dos textos. Nesse sentido, a leitura e a tradução passam a sofrer de "eis-egesis": projeçâo ou 
introdução de categorias e pontos de vista pessoais. Isso também explica porque existem leituras tão diferentes de autores antigos dependendo do background filosófico e cultural de quem os apresenta. Mas ele considera que o componente subjetivo pode ser minimizado levando a traduçôes e interpretaçôes mais objetivas e autênticas. Ao ouvir o prof. Giuseppe não deixa de surgir a percepção de que uma tradução técnica é possível, como, por exemplo, em aplicativos de tradução que são diretos e cumprem certa função. Em pesquisas universitárias não é raro submeter a análise de um material a vários pesquisadores para avaliar se chegam no mesmo resultado. Essa poderia ser uma possibilidade metodológica. Mas ele confirma que o conhecimento geral do contexto da tradução de textos budistas deve estar presente nos tradutores que se dedicam a tal empreitada. Igualmente, enfatiza a necessidade de domínio por parte do tradutor ou tradutora da língua portuguesa e dos seus usos. Isso faz pensar na complexidade da tradução para o português do Brasil em que os termos mudam conforme a regiáo, além das transformaçóes temporais as quais o prof. Giuseppe também se refere.

Além desses domínios, no caso da tradução de obras indianas já traduzidas em outras línguas modernas ocidentais, o tradutor precisa conferir cada palavra valendo-se da maior quantidade possível de literatura secundária, para conhecer o que de mais importante foi já publicado e debatido sobre o material em questão. Em função dessas múltiplas qualidades necessárias, nada mais natural do que envolver equipes de estudiosos nas traduçóes, cada um contribuindo com qualidades específicas. O prof. Giuseppe dá um exemplo disso contando uma experiência acadêmica que envolveu uma equipe. Foram em duas ocasiōes, nos anos 2014 e 2015, na UFMG. O professor Leonardo Vieira organizou um seminário para ler, interpretar e traduzir o capítulo 15 dos Versos Fundamentais do Caminho do Meio de Nāgārjuna. Cada um dos cinco convidados do evento - todos estudiosos de budismo - tinha um background e, portanto, uma abordagem diferente do texto em questão: a doutora Ana Paula Gouveia, tibetóloga, lia o texto na sua versão em tibetano; o professor Joaquim Monteiro, devido à sua formaçáo de sinólogo, usava a versão chinesa do mesmo texto; os professores Dilip Loundo e Giuseppe, mais familiarizados 
com a tradição indiana do budismo, abordavam o texto original em sânscrito; finalmente, o professor Vieira, de formação filosófica mais propriamente "ocidental", mas estudioso da escola Madhyamaka e capaz de transitar entre sânscrito e o mandarim, era o elemento de conexão entre as diferentes linguagens e tradiçóes exploradas nos seminários. Os encontros de dois dias se desenvolveram durante muitas horas, durante as quais os meros 11 versos do capítulo em questão foram literalmente desmembrados: cada uma das poucas dezenas de palavras do pequeno texto foram analisadas e debatidas a partir dos diferentes pontos de vista de cada um e, naturalmente, através dos vários comentários existentes. A escolha dos termos em português nos quais verter os originais sânscritos/tibetanos/chineses foi extraordinariamente ponderada, levando em conta inúmeras possíveis nuances filosóficas e filológicas de cada palavra. O resultado do encontro - concretizado no livro Nāgārjuna: Exame do ser e do não-ser, publicado pela editora Phi em 2018 - foi uma tradução que, mesmo que não possa ser considerada "objetiva", "verdadeira" ou definitiva, certamente atenuou os elementos de subjetividade que uma leitura individual poderia apresentar.

Nesse exemplo pode-se observar a sofisticação e o rigor deste tipo de tradução. Atualmente essa metodologia pode se realizar de forma on-line aproximando a tradução da intenção original do autor. O prof. Giuseppe ressalta que os espaços institucionais e recursos financeiros são imprescindíveis para isso, bem como é importante e necessário que o estudo da filosofia da Índia e de outras tradiçôes asiáticas, aqui no Brasil, se torne mais "acadêmico", embora ele reconheça que os pensamentos budista e hinduísta têm sido cada vez mais respeitados na academia brasileira, ainda que haja bastante ignorância e desinformação com relação às filosofias da Índia e do Oriente extremo. Talvez os filósofos contemporâneos não conheçam bem e nem tenham interesse pelas antigas tradiçôes indianas. Entretanto dificilmente argumentarão alegando que o pensamento de Nāgārjuna, Vasubandhu, Dharmakīrti ou de muitos outros autores indianos e de outras tradiçóes asiáticas não seja "filosófico" e, portanto, digno de ser explorado dentro de uma faculdade de filosofia. Mas ainda assim, a presença acadêmica das filosofias 
orientais na academia brasileira não é comparável à que encontramos em diversas universidades europeias e norte-americanas. Prof. Giuseppe estima que haja no Brasil um número de talvez 20 ou 30 estudiosos que têm boa familiaridade com as filosofias da Índia e que, há alguns anos, fazem um trabalho de estudo e divulgação; entretanto, não parecem haver perspectivas de continuidade de uma sólida geração de novos pesquisadores que dêem continuidade a esse trabalho de exploração e "desbravamento" dos territórios filosóficos. O perigo, segundo ele, é que as atividades de pesquisa dos hindólogos, nipólogos, tibetólogos e sinólogos brasileiros, ainda que embrionárias, acabem se atrofiando ou se extinguindo.

É interessante acompanhar a linha de raciocínio do prof. Giuseppe, pois há um alerta veemente para que não percamos de vista a riqueza do conhecimento oriental (que não é só do oriente mas de todos). Ele exemplifica que, atualmente, um estudante de filosofia que queira fazer sua pós-graduação no pensamento grego clássico, terá dificuldade em encontrar uma temática original, que ainda não tenha sido explorada e discutida amplamente. Ao contrário, no que diz respeito à filosofia da Índia, ainda existem fontes primárias de extraordinário valor filosófico que não foram traduzidas em nenhuma língua ocidental - ou que, até mesmo, se encontram não editadas, ou seja, na forma de manuscrito - e, muito menos, estudadas e difundidas. As oportunidades de pesquisa nesse setor são, portanto, inúmeras. Textos de importância crucial na história do pensamento universal ainda esperam ser traduzidos para o português e se tornar objeto de leitura, interpretação e discussão acadêmica. Enfim, estamos falando de uma verdadeira mina de sabedoria, que espera ser explorada. Não há dúvida que o assim chamado ocidente se enriqueceria com toda essa cultura, tradição e filosofia antiga da Índia.

Por outro lado, o prof. ressalta que há um público interessado nestes temas tanto para produzir materiais quanto para consumi-los, seja lendo, ouvindo ou assistindo eventos e vídeos. O prof. encerra sua exposição afirmando que as perspectivas e os estilos de vida concebidos na Ásia oriental se apresentam, para muitos de nós, como uma referência segura e um fundamental ponto de orientação. Essa parece ser uma excelente justificativa para que os estudos acadêmicos do budismo no Brasil cresçam. 


\section{Beatriz Bispo}

Bia Bispo (como é conhecida) é tradutora e intérprete (direta) de SS Dalai Lama, traduzindo e interpretando simultaneamente tanto do inglês quanto do tibetano para o português. Igualmente, traduz escrituras budistas.

Bia nasceu no Brasil, mas mora fora do país há quase 40 anos. Ela nos conta que seu primeiro contato com o budismo aconteceu na Itália em 1990, diretamente com o Dalai Lama. Logo após esse encontro, ela começou a estudar no Instituto Budista Samantabhadra, em Roma, com Gheshe Sonam Cianciub da escola Gelug. Permaneceu um bom tempo estudando na Escola Gelug, uma tradição budista fundada pelo mestre Lama Tsong Khapa, e faz o uso do raciocínio lógico e dos debates para compreender profundamente os significados dos tratados filosóficos. Em 1992, dois anos após ter conhecido o Dalai Lama, largou sua vida em Roma e se transferiu para Dharamsala, na Índia, para estudar direto da fonte, e, também, aprender sobre o tibetano. A história da Bia é estimulante de ser lida e compartilhada, pois sendo mulher e brasileira, tendo trilhado um percurso único, pode ser de grande inspiração para as brasileiras que almejam seguir um caminho espiritual.

Estando em Dharamsala, começou seus estudos na LTWA (Library Tibetan Works and Archives) com o mestre Geshe Dawa, também da tradição Gelug. Neste mesmo ano encontrou aquele que veio a considerar o seu mestre na tradição Nyingma, Garje Khamtrul Rinpoche Jamyang Dondrup da Escola Nyingma, que naquele tempo era o Secretário Geral do Departamento de Relaçóes Culturais e Religiosas Tibetano e um dos principais assistentes diretos do Dalai Lama. Nessa tradição os métodos de aprendizagem são diferentes, ou seja, não tem muita ênfase na lógica, como na tradição Gelug. Usa-se muito a prática de observar e analisar a mente. Ademais, como todas as tradições ou escolas budistas tibetanas, cada uma tem seus métodos de ensinos e práticas individuais.

Bia sempre se mostra muito modesta e acessível nas suas falas públicas, repete e enfatiza que não possui títulos e que é apenas a Bia, sem formação, nem doutorado, nem se considera professora. Com um estilo de humor 
particular, conta que essa coisa de título e diplomas é, para ela, algo pelo qual sempre teve algum tipo de aversão, nunca deu importância, assim como teve e tem aversão a "uniformes ou divisas". Talvez ela se refira às formalidades que acabam gerando bastante superficialidade no conhecimento. Mas, conhecendo o trabalho da Bia, ouvindo e lendo suas traduçôes, conseguimos ver uma praticante séria, experiente, dedicada e muito perspicaz. Ela mesma conta que desde pequena foi (e ainda é) muito interessada em aprender, estudar, ler e ter conhecimento, e isso, para ela, é o foco principal da vida, nunca aspirou algum grau superior de estudo, como o doutorado.

Ela estuda budismo há 30 anos, mas ao se referir a essas três décadas já trata de se retratar afirmando que isso náo quer dizer nada, porque uma pessoa pode estudar muito e não saber nada. Hoje, ela é a intérprete de Dalai Lama. Apesar da enorme distinçáo de ser a única brasileira, mulher, intérprete de Dalai Lama, diz que isso "de ser intérprete e de traduzir seus livros" foi algo para o qual foi empurrada. Seu tom é de que isso aconteceu ao acaso. Conta a respeito do panorama da época em que foi para Dharamsala dizendo que durante os ensinamentos não havia intérprete e náo tinha outra pessoa, na ocasiáo, que falasse português e, ao que parece, por estar na hora e local certos, ela foi a única a poder assumir a função. Foi entâo que o tradutor do Dalai Lama, hoje diretor do LTWA, Geshe Lhakdor, insistiu para que ela interpretasse para os brasileiros que vinham para os ensinamentos de S.S. Dalai Lama, até que ela aceitou e passou a ser intérprete dos seus ensinamentos. Por ser ela a única brasileira morando em Dharamsala, conta que acabou sendo um ponto de referência para os brasileiros que lá chegavam e, com isso, conheceu muitas pessoas de várias partes do Brasil, muito mais do que quando morava em Brasília. Entáo, por meio deles, ficava sabendo sobre o budismo que acontecia no país.

Em 2006, mais ou menos depois de 12 a 13 anos que estava lá, pediu uma audiência particular com a Sua Santidade para perguntar o que ela poderia fazer para contribuir com o budismo no Brasil. Essa foi a sua primeira audiência privada com Sua Santidade o Dalai Lama. Foi nessa audiência que ele pediu a ela que traduzisse alguns textos, alguns livros clássicos, e 
que, quando viesse para o Brasil, começasse a ensinar para pequenos grupos formados por amigos, familiares etc. Nesse momento, ela conta ter tentado se desvincular dessa responsabilidade e ter dito a ele que não tinha capacidade para tanto, que não era professora, que ainda estava estudando e que não poderia ensinar. Ele respondeu: "Ok, se você não quer ensinar, você faz grupos de estudos e lidera os grupos. Ensinar é fácil, você diz o que você sabe, e o que não sabe, você diz que não sabe”.

Bia falou que, quando se mudou para lá, queria apenas estudar, praticar e ser uma pessoa melhor, nunca aspirou nada do que veio a viver após. Ela ia seguindo sua vida, mas, por vezes, surgia a lembrança da orientação de seu mestre para ensinar e a traduzir livros. Até que em 2010 criou coragem e contatou uma amiga, pedindo para que ela ajudasse a encontrar uma editora. Nessa ocasião, já havia traduzido um livro do Dalai Lama, que enfatiza não ser uma tradução de boa qualidade. Tendo morado fora do Brasil por muito tempo, estudou budismo em inglês, italiano e tibetano mas não em português. Apesar disso, montou alguns grupos de estudos em algumas cidades do Brasil e se concentrou em traduzir mais livros para o português. Em 2013, ela teve uma segunda audiência com Sua Santidade para contar o que havia feito no Brasil, agradecer a sua confiança e dizer que não queria mais trabalhar com grupos de estudos. Entretanto, ele a orientou a continuar, ficar mais tempo no Brasil e a traduzir o livro "Além da Religião: Uma Ética Por Um Mundo Sem Fronteiras”. Após a tradução do livro, o Escritório de Sua Santidade o Dalai Lama solicitou a ela para traduzir o primeiro volume da série, "Ciência e Filosofia nos Tratados Budistas Indianos Clássicos - O Mundo Físico", o qual já foi publicado em inglês. Refere-se aos mestres da tradição da Universidade de Nalanda e menciona desde os ensinamentos de Buddha, das escolas Sarvastivada, o Abhidharma, até a escola Madhyamaka. Nesse, havia a presença da terminologia clássica que ela relata ter tido dificuldades para traduzir, apesar de ter sido de grande ajuda o seu conhecimento da língua tibetana e o conhecimento da filosofia budista tibetana clássica e da dialética. Ela conta, um pouco dando conselhos aos jovens tradutores, que se fosse mais jovem estudaria o sânscrito, porque saber tanto o tibetano quanto 
o sânscrito realmente é muito útil para a tradução desses textos clássicos. Ela também refere que ter um conhecimento profundo dessa filosofia, derivado do estudo dos textos clássicos e seus comentários, ter recebido explicaçôes de mestres qualificados e não só ter lido livros, foi crucial para uma ótima tradução. Para finalizar sua exposição deu alguns exemplos de traduções em que precisou estudar a fundo e, por vezes, inclusive, buscar uma terminologia própria para melhor expressar o significado.

O principal exemplo, e que parece o mais significativo de retratar aqui, por se tratar de uma palavra muito usada em português, é o conhecido termo "vacuidade". Bia adotou o termo "vaziedade" e não "vacuidade", citando os trabalhos de Jesus (2010, p. 68), e Vázquez (2014) em função desse termo traduzir profundamente o significado encontrado nos tratados do budismo clássico indiano. Com originalidade, Bia aponta que esse termo é mais próximo da tradução literal dos idiomas sânscrito, tibetano e até mesmo do inglês. Ela esclarece brevemente que o termo vacuidade deriva de vácuo e não de vazio. Da mesma forma, "vacuidade" não corresponde nem ao tibetano tonpani e nem ao sânscrito shuniata. A tradução de vacuity ou "vacuidade" em tibetano significa simplesmente "vazio", o que é completamente diferente do significado de emptiness ou shuniata no contexto filosófico budista.

Bia parece muito segura e corajosa ao propor uma nova nomenclatura de um termo que já vem tendo essa tradução (de vacuidade) para o português. Ele menciona a importância de compreender esse tipo de "vaziedade", o que é um fator crucial para entender a filosofia e as práticas budistas. Para tanto, alega ser indispensável o estudo da etimologia e a definição apropriada das palavras, bem como conhecer o contexto de cada escola filosófica, em especial quando se tratam de traduçóes do budismo clássico. Ela alerta que uma mesma palavra pode significar coisas completamente diferentes em variadas escolas. Nesse sentido, muitos erros poderiam ser evitados já que decorrem da falta de conhecimento profundo do texto e da compreensão da definição etimológica das terminologias. Igualmente, muitos vieses são driblados, como aqueles mencionados pelos profs. Giuseppe e Ricardo, concernentes ao excesso do componente subjetivo e interpretativo na tradução. Uma das preocupaçóes de 
Bia é a perduração do significado mais autêntico. Para isso, sugere que sejam criados catálogos com um vocabulário homogêneo de tradução de textos budistas e que a padronização seja um dos principais parâmetros.

Ela explica que muitas palavras foram "aportuguesadas" sem unicidade nas escolhas. Aposta que a adoção de palavras do sânscrito e do tibetano mantendo a fonética original possa preservar os significados genuínos. Dá exemplos de alguns termos nessa situação como: Buddha, sangha, samaya. Como o budismo é relativamente novo no Brasil, Bia considera que ainda é possível mudar os rumos de sua evolução através de uma tradução cuidadosa. É isso, então, o que acontece com as filosofias de todas as tradiçóes religiosas e, visto que no Brasil o budismo é relativamente novo em comparação com outros países, ainda dá tempo de impedir seu acontecimento.

\section{CONSIDERAÇÓES FINAIS}

As principais preocupaçóes dos expoentes versam sobre importantes questôes do budismo no presente momento que vivemos, suas possibilidades e desafios. Tanto em suas falas quanto em alguns autores citados acima, o budismo se encontra em uma fase de expansão e florescimento, no assim chamado Ocidente (países não asiáticos), e há uma preocupação de como se dará essa continuidade especificamente no Brasil, tendo em vista suas variadas segmentaçóes e ramificaçóes. O hiato cultural entre o Brasil e os países asiáticos deixa pairar uma incógnita: será um budismo traduzido mantendo o significado original ou será um novo budismo brasileiro? No caso do budismo, que é basicamente asiático, oriental, regional e oriundo de vários lugares da Ásia, ao chegar no Brasil deveria ser traduzido como um todo e não apenas as suas palavras. Como parece que esse processo é pulverizado e não realizado de forma sistemática, não se sabe ao certo que budismo ou budismos teremos no Brasil daqui a um tempo.

O diálogo do budismo com a academia surge como um tema em que é apresentada a necessidade e a dificuldade de estabelecer esse debate. Duas principais dificuldades foram apontadas: 1) o já conhecido antagonismo 
presente implicitamente no binômio religiáo-ciência; 2) trabalhos acadêmicos sobre budismo são esparsos e pulverizados em diferentes linhas de pesquisa e áreas do conhecimento, o que dificulta sua visibilidade e fortalecimento. Outra dificuldade é a de que, no budismo, muito do conhecimento gerado não se deu apenas dentro das instituiçōes religiosas, filosóficas ou acadêmicas, mas sim na individualidade de praticantes reclusos que desenvolviam alto grau de entendimento e realização através da prática direta e em isolamento. Dessa forma, o diálogo passaria a ser entre a academia e a tradiçáo; ou em estudos sobre a tradição em questão.

Em todo caso, a título de conclusão provisória, a tradição budista segue sendo um espaço de estudo e erudição em si com métodos e racionalidade própria. E a universidade tem a sua própria variedade de métodos e visốes de ciência conforme campos de estudo. Mantidas essas diferenças e nenhuma possibilidade de integração é possível fazer ciência em diálogo com o budismo, assim como ser budista e acadêmico, como os expoentes deste simpósio nos mostraram.

\section{REFERÊNCIAS}

BARROZO, Victor Breno Farias. Rostos de um Budha Tupiniquim: breve panorama social do budismo no campo religioso brasileiro. PARALELLUS Revista de Estudos de Religião - UNICAP, Recife, v. 7, n. 16, p. 483-499, 2016.

BELUZZI, Ethel Panitsa. Tradução de textos da filosofia oriental: peculiaridades e requisitos no caso da filosofia budista. Rónai - Revista de Estudos Clássicos e Tradutórios, Juiz de Fora, v. 3, n. 2, p. 95-107, 2015.

BEZERRA, Paulo. A tradução como criação. Estudos Avançados, São Paulo v. 26, n. 76, p. 47-56, 2012.

BOTELHO, Octavio da Cunha. A problemática da tradução dos upanixades. Revista de Estudos Orientais, São Paulo, n. 5, p. 65-80, 2006. 
BRONKHORST, Johannes. Modes of debate and refutation of adversaries in classical and medieval India: a preliminary investigation. Antiqvorvm Philosophia, Roma, v. 1, p. 269-280, 2007.

CARLUCCI, Bruno. As Linhagens de Monges-Tradutores no fluxo do budismo da Índia para o Tibete. In-Traduçóes Revista do Programa de Pós-Graduação em Estudos da Tradução da UFSC, Florianópolis, v. 7, n. 11, p. 25-40, 2015. FERRARO, Giuseppe. As duas verdades de Nāgārjuna nos comentários de Bhāviveka e Candrakīrti. Kriterion: Revista de Filosofia, Belo Horizonte, v. 57, n. 133, p. 43-63, 2016.

FERRARO, Giuseppe. differenza epistemologica e identità ontologica tra sa? s? ra e nirv?? a nel pensiero buddhista. TRANS/FORM/AÇÃO: Revista de Filosofia, Marília, v. 35, n. 1, p. 193-212, 2012.

FERRARO, Giuseppe. Alguns momentos do debate sobre as teorias do'não-si'e das' duas verdades' na história da filosofia buddhista. Kriterion: Revista de Filosofia, Belo Horizonte, v. 52, n. 123, p. 7-29, 2011.

GONÇALVES, Ricardo Mário. As flores do dharma desabrocham sob o Cruzeiro do Sul: aspectos dos vários" budismos" no Brasil. Revista USP, São Paulo, n. 67, p. 198-207, 2005.

GONÇALVES, Ricardo Mário. A introdução do Budismo no Japão. Estudos Japoneses, São Paulo, v. 8, p. 53-60, 1988.

GONÇALVES, Ricardo Mário. Consideraçôes sobre o culto de amida no Japão Medieval: um exemplo de consciência histórica no Budismo Japonês. Revista de História, São Paulo, v. 45, n. 91, p. 39-58, 1972.

JESUS, Dália Maria André et al. Produção e reconhecimento de substantivos abstractos deadjectivais em português L2. 2010. Tese (Doutorado em Letras) Faculdade de Letras, Universidade de Coimbra, Coimbra, 2010.

MENESES, Ariel Daltrozo Munhoz. Uma lamparina para o caminho da iluminação: tradução indireta e comentada de um texto budista tibetano. 2017. Trabalho de Conclusão de Curso (Graduação em Letras) - Universidade Brasília, Brasília, 2017. 
MONTEIRO, Joaquim Antonio Bernardes Carneiro. As bases filosóficas do Budismo chinês. Editora Phi: Campinas, 2021.

MONTEIRO, Joaquim Antonio Bernardes Carneiro. Ética e subjetividade no Budismo chinês contemporâneo. Educação e Filosofia, Uberlândia, v. 33, n. 69, p. 1189-1221, 2019.

MONTEIRO, Joaquim Antônio Bernardes Carneiro. As "duas verdades" na perspectiva do "Satya-siddhi-šăstra": Um contraste com a visão de Nāgārjuna. Kriterion: Revista de Filosofia, Belo Horizonte, v. 57, n. 133, p. 85-103, 2016. MONTEIRO, Joaquim Antônio Bernardes Carneiro. Filosofia budista: uma breve introdução. Ensaios filosóficos, Rio de Janeiro, v. 11, p. 104-124, 2015. SASAKI, Ricardo. Motorcycle and the Art of Zen. Journal of the International Association of Buddhist Universities (JIABU), Phra Nakhon Si Ayutthaya, v. 8, n. 2, 2017.

SASAKI, Ricardo. O Caminho Contemplativo: um guia para meditação. Petrópolis: Vozes, 1995.

USARSKI, Frank; SHOJI, Rafael. Perspectiva sociológica sobre a expansão do Budismo e das religiōes japonesas no Brasil. REVER-Revista de Estudos da Religiāo, São Paulo, v. 17, n. 2, p. 99-118, 2017.

VÁZQUEZ, Ana Araujo. A (re)escritura da Eternidade Dourada, de Jack Kerouac. 2014. 52 f. Trabalho de Conclusão de Curso (Licenciatura em Letras Português) - Universidade de Brasília, Brasília, 2014.

Recebido em: 29/05/2021

Aprovado em: 06/10/2021 